\title{
Proposições do Banco Mundial para a política educacional brasileira (2016-2018)
}

\author{
Dhyovana Guerra ${ }^{1}$ \\ ORCID: 0000-0002-1026-606X \\ Ireni Marilene Zago Figueiredo ${ }^{1}$ \\ ORCID: 0000-0001-8875-7099
}

\section{Resumo}

0 presente artigo tem por objetivo discutir as proposições do Banco Mundial para a Política Educacional brasileira entre os anos 2016 e 2018. Para tanto, são discutidos excertos de quatro documentos emanados do Banco Mundial (2016, 2017a, 2017b, 2018), um Organismo Internacional que atua na concessão de empréstimos e oferece assessoria técnica aos países membros, assim como desempenha uma função expressiva na produção intelectual, por meio da elaboração de um conjunto de documentos que subsidiam a implementação das políticas educacionais. No estudo realizado constata-se a ênfase do Banco Mundial na reforma do Estado e da educação, cujo atendimento das necessidades educacionais básicas é considerado como uma das variáveis fundamentais para administrar os níveis de pobreza. Por meio da educação, que promoveria a aquisição de habilidades e competências durante a formação escolar, seria possível conseguir emprego e, consequentemente, obter renda para redução da pobreza. Ao que tudo indica, a educação, nos quatro documentos do Banco Mundial analisados, é concebida como elemento central para o alívio dos efeitos da pobreza e para promoção da equidade. A educação também é apontada como uma das responsáveis pela ineficiência dos gastos públicos no Brasil, o que tende a expressar um alinhamento ao projeto neoliberal de sociedade, a partir da década de 1990.

\section{Palavras-chave}

Política educacional brasileira - Banco Mundial - Neoliberalismo - Pobreza.

1- Universidade Estadual do Oeste do Paraná (Unioeste). Cascavel, Paraná, Brasil. Contatos: dhyovanaguerra@hotmail.com; irenifigueiredo@ hotmail.com 


\section{World Bank proposals for Brazilian educational policy (2016-2018)}

\section{Abstract}

In this article, we discuss the proposals of the World Bank for Brazilian education policy from 2016 to 2018. To this end, we examined excerpts from four documents issued by the World Bank (2016, 2017a, 2017b, 2018), an international organization that provides loans and technical advice to member countries, as well as plays an expressive role in intellectual production, through the preparation of a set of documents that subsidize the implementation of educational policies. We found in our study a World Bank's emphasis on state and education reform, in which the fulfillment of basic educational needs is considered as one of the fundamental variables to manage poverty levels. It would be possible through education, which promotes the acquisition of skills and competencies during the school years, to foster jobs and consequently obtain income to reduce poverty. It seems that education is conceived as a central element for alleviating the effects of poverty and promoting equity in the four World Bank documents analyzed. Education is also pointed out as one of the reasons for the inefficiency of public spending in Brazil, which tends to express an alignment with the neoliberal project of society, starting in the 1990s.

\section{Keywords}

Brazilian educational policy - World Bank - Neoliberalism - Poverty.

\section{Introdução}

Este artigo apresenta o estudo da política educacional brasileira a partir da década de 1990 que está, em parte, relacionada a reforma do Estado brasileiro e, portanto, responde ao processo de satisfação das necessidades educacionais básicas, visando administrar os níveis de pobreza. Do mesmo modo, os Organismos Internacionais passaram a interferir sistematicamente na educação dos países em desenvolvimento, sob a justificativa da prioridade do ensino elementar/básico, que do ponto de vista econômico, daria maior retorno e, politicamente, promoveria a equidade.

Dentre os Organismos Internacionais, destaca-se neste estudo o Banco Mundial, que concede empréstimos aos países membros, bem como produz um conjunto de documentos que expressa uma produção ampla de conhecimentos para e sobre os países aos quais os empréstimos são concedidos. Ressalta-se, também, a função intelectual do Banco Mundial que, por meio das publicações direcionadas particularmente aos países em desenvolvimento, faz recomendações para a implementação de políticas públicas. 
0 artigo, desse modo, tem por objetivo discutir as proposições do Banco Mundial para a política educacional brasileira entre os anos $2016^{2}$ e 2018. Para tanto, são discutidos excertos de quatro documentos emanados do Banco Mundial, no período delimitado para estudo, sendo: Retomando o caminho para a inclusão, o crescimento e a sustentabilidade (2016); Informe sobre el desarrollo mundial 2018 - Mensajes principales: aprender para hacer realidad la promesa de la educación (2017a); Um ajuste justo: Análise da eficiência e equidade do gasto público no Brasil (2017b); e Informe sobre el desarrollo mundial 2018: Aprender para hacer realidad la promesa de la educación (2018).

Estes quatro documentos do Banco Mundial compuseram o corpus documental da pesquisa de dissertação de mestrado de Guerra (2020) que abordou, em parte, a interferência e as proposições dos Organismos Internacionais nas políticas de educação infantil e do ensino fundamental (2006-2016). Os documentos expressaram a continuidade da política do Banco Mundial desde a década de 1990, ao mesmo tempo em que este responde às novas demandas sociais.

Recorre-se ao documento O Estado num mundo em transformação (BANCO MUNDIAL, 1997), para explicitar como as proposições do Banco Mundial continuam a impactar na formulação das políticas sociais e educacionais no atual contexto. A análise fundamenta-se, também, nos estudos de Fonseca (1998a, 1998b); Tommasi (1998); Arruda (1998); Coraggio (1998); Silva (2000, 2002); Oliveira e Fonseca (2001); Frigotto e Ciavatta (2003); Figueiredo (2006, 2009); Zanardini, I. (2007); Zanardini, J. (2008); Pereira (2009, 2018); Deitos (2010); Shiroma, Moraes e Evangelista (2011); Evangelista e Leher (2012); e Evangelista e Triches (2012).

\section{Aspectos da interferência do Banco Mundial na Política Educacional brasileira}

A política educacional empreendida no Brasil a partir da década de 1990 representou a articulação entre forças econômicas e políticas hegemônicas fundamentadas pelo neoliberalismo. Na referida década, os Organismos Internacionais passaram a interferir sistematicamente nas questões educacionais dos países da América Latina e Caribe, particularmente no que diz respeito à política educacional, por meio de assessorias técnicas e pedagógicas, organização de conferências internacionais e da elaboração de diversos documentos (FRIGOTTO; CIAVATTA, 2003; DEITOS, 2010; SHIROMA; MORAES; EVANGELISTA, 2011).

Dentre esses Organismos Internacionais, centramos a análise em quatro documentos do Banco Mundial, um organismo multilateral de financiamento, criado em 1944, que atua com operações de crédito, financiamentos e investimentos para projetos de diversas áreas. Convém esclarecer, inicialmente, que o Grupo Banco Mundial é composto atualmente por 189 países membros e conta com funcionários de mais de 170 países:

2- Dilma Vana Rousseff democraticamente reeleita, em 2014, foi destituída do governo pelo processo de impeachment em 31 de agosto de 2016, assumindo a presidência o vice-presidente Michel Miguel Elias Temer Lulia (PMDB). 
0 Grupo Banco Mundial, uma das fontes mais importantes de financiamento e conhecimento para os países em desenvolvimento, é composto por cinco instituições que estão comprometidas em reduzir a pobreza, aumentar a prosperidade compartilhada e promover o desenvolvimento sustentado. (GRUPO BANCO MUNDIAL, 2019, s/p, tradução nossa) ${ }^{3}$.

As cinco instituições vinculadas ao Grupo Banco Mundial são: o Banco Internacional para a Reconstrução e Desenvolvimento (BIRD); a Agência Internacional de Fomento (AIF); a Corporação Financeira Internacional (CFI); a Agência de Garantia de Investimentos Multilaterais (MIGA); e o Centro Internacional para a Resolução de Disputas sobre Investimentos (ICSID). Cada instituição possui seus próprios órgãos governamentais, acordos constituintes e países membros, sendo que o Brasil passou a integrar o BIRD em 1946, a CFI em 1956, a AIF em 1963, a MIGA em 1993, e não integra a ICSID (GRUP0 BANCO MUNDIAL, 2019).

Contudo, o Banco Mundial, que fornece financiamento e assessoria técnica aos governos de países em desenvolvimento, é composto apenas pelo BIRD e pela AIF. O BIRD possui atividades lucrativas e concede empréstimos para o setor público dos países mais pobres de renda média, em condições próximas às de mercado. A AIF, por sua vez, depende de contribuições voluntárias e realiza empréstimos a longo prazo aos países pobres, com pouca capacidade de fazer empréstimos nas condições de mercado. As parcerias com o setor privado são realizadas pela CFI, MIGA e ICSID (GRUPO BANCO MUNDIAL, 2019).

Fonseca (1998a) sinaliza que o Banco Mundial/BIRD atua no setor público brasileiro como agência financiadora na área de infraestrutura desde a década de 1940, mas, a partir da década de 1970 tornou-se a maior e mais relevante fonte de financiamento no setor social. Junto ao Fundo Monetário Internacional (FMI), o Banco Mundial atuou, ainda, na condução do processo de reforma e modernização do Estado brasileiro que, iniciada na década de 1990, constituiu uma das condicionalidades dos empréstimos para os ajustes estruturais e setoriais, por meio do processo de renegociação da dívida externa e da abertura comercial.

Para o Banco Mundial, a rigor, são considerados como investimentos sociais os financiamentos à saúde e nutrição, à educação, à questão populacional, ao desenvolvimento urbano e ao abastecimento de água e saneamento. Nesse sentido,

Na metade da década de 1970, saúde e educação passaram a ser incluídas entre os mais importantes, tendo em vista o seu potencial para a redução da pobreza. 0 setor social brasileiro recebeu, no período 1970-1990, cerca de 15\% do total de créditos, sendo 1,6\% para a educação. A assignação de recursos à saúde, no Brasil, inicia-se na década de 1980, correspondendo a 1,7\% em relação aos créditos sociais. (GONZALEZ, 1990 apud FONSECA, 1998a, s/p).

Entre 1980 e 1995 foram quatro projetos executados com o Ministério da Educação (MEC), sendo três deles destinados ao ensino primário, aos municípios com taxa de

3 - "El Grupo Banco Mundial, una de las fuentes más importantes de financiamiento y conocimiento para los países en desarrollo, está integrado por cinco instituciones que se han comprometido a reducir la pobreza, aumentar la prosperidad compartida y promover el desarrollo sostenible" (GRUPO BANCO MUNDIAL, 2019, s/p). 
crescimento populacional acima de 4\% ao ano, o que já demonstrava a influência do Banco Mundial na educação brasileira (FONSECA, 1998a). Na década de 1990, a intervenção do Banco Mundial no ensino fundamental brasileiro teve um total de financiamento combinado de cerca de 1 bilhão de dólares (TOMMASI, 1998), com a aprovação de seis projetos, que contemplaram treze estados brasileiros ${ }^{4}$.

0 processo de negociação de projetos para o setor educacional brasileiro, entre o Brasil e os Organismos Internacionais, está permeado por contradições e interferências de interesses econômicos e políticos nacionais e internacionais. Dessa forma, os processos que permeiam os acordos internacionais não são homogêneos, ao contrário, as negociações e a execução dos projetos de financiamento são complexas e demoradas, considerando os diferentes interesses.

Baseado na experiência brasileira,

[...] é possível afirmar que a cooperação técnica e financeira do Banco Mundial não constituiu uma interação neutra, mas um mecanismo de difusão de concepções internacionais, especialmente aquelas que emanam do próprio órgão financiador. Estas incluem desde aspectos instrumentais, como modelos de planejamento e de gestão de projetos, até as formulações conceituais e ideológicas, capazes de orientar a agenda do setor sob financiamento. (OLIVEIRA; FONSECA, 2001, p. 64).

A partir da década de 1970 e, principalmente, na década de 1990, na América Latina, a educação ganhou maior importância nas formulações do Banco Mundial, uma vez que teria uma função decisiva no crescimento econômico, de modo particular no tocante à educação básica para a população pobre. A produtividade dos pobres assumiu grande importância para o Banco Mundial que incluiu a educação, a saúde e o desenvolvimento rural em seu quadro de crédito, que inicialmente era restrito a projetos de infraestrutura, a fim de proporcionar os elementos essenciais para o aumento da produtividade (FONSECA, 1998a).

0 alinhamento brasileiro às políticas e estratégias do FMI e do Banco Mundial foi acelerado em 1991 com a sua submissão consentida ao plano de estabilização e aos ajustes das reformas institucionais. Do mesmo modo, as políticas educacionais referentes à educação básica pública foram orientadas em consonância com o projeto econômico implementado nos países da América Latina. Assim, a interferência das instituições financeiras internacionais se dá por meio da subordinação dos governos a um conjunto de condições que são estabelecidas previamente para a concessão de empréstimos (SILVA, 2002).

0 Banco Mundial argumenta que a falta de reformas na educação tem acarretado custos econômicos, sociais e políticos aos países em desenvolvimento e não as realizar impediria a promoção da qualidade, da produtividade, e da modernização e inserção do país ao processo de globalização (FIGUEIRED0, 2006; ZANARDINI, I., 2007). Nesse

4 - Dos seis projetos, dois continuaram para a região do Nordeste, com abrangência para todos os estados: "Educação Básica no Nordeste II" (Maranhão, Ceará, Pernambuco e Sergipe) e "Educação Básica no Nordeste III" (Piauí, Rio Grande do Norte, Paraíba, Alagoas e Bahia). Os demais projetos foram para os estados de Minas Gerais - "Projeto de Melhoria da Qualidade da Educação Básica em Minas Gerais"; São Paulo - "Projeto Inovações na Educação Básica em São Paulo" (INOVAÇÕES); Espírito Santo - "State of Espírito Santo Basic Education Project"; e Paraná - "Projeto Qualidade no Ensino Público do Paraná" - PQE. 
raciocínio, o Estado deveria ser responsável pela oferta dos serviços básicos em educação e saúde, visando manter a pobreza em níveis suportáveis, a fim de garantir as condições mínimas para implementação das políticas de ajuste econômico (FIGUEIRED0, 2006).

0 Banco Mundial vem ampliando as suas funções no sentido de atuar cada vez mais como órgão político central, especialmente como coordenador do processo global de desenvolvimento (FONSECA, 1998a, 1998b), e por meio da produção de uma série de documentos políticos que sustentam o referencial teórico-conceitual para a área da política econômica e social. Por isso, dentre os conceitos advindos dos documentos do Banco Mundial que fundamentam o processo de financiamento e, ao mesmo tempo, influenciam na elaboração das políticas de educação brasileira destacam-se: desenvolvimento econômico, desenvolvimento sustentável, autonomia, equidade, pobreza, aprendizagem, eficiência e justiça.

0 acordo que constituiu o Banco Mundial/BIRD determina a não intervenção na política dos países membros. Entretanto, quando se tornou mentor dos governos do Hemisfério Sul passou a exercer grande influência na política dos países em desenvolvimento e, apesar de defender o livre mercado, é uma instituição intervencionista. Nessa direção, uma de suas principais ações inclui a prestação de assessorias aos países, por meio da produção de conhecimentos (CORAGGIO, 1998; ARRUDA, 1998; PEREIRA, 2009).

As pesquisas que embasam as assessorias prestadas pelo Banco Mundial, produzem evidências até mesmo contrárias às suas próprias recomendações, o que pode estar relacionado à correlação de forças internacionais, somada às análises microeconômicas. Para exemplificar, pontuamos a discrepância entre o discurso para a melhoria da qualidade na educação e a proposição de redução de recursos para as políticas sociais. A ênfase na educação não se limita, portanto, nas linhas de crédito de financiamento, mas na indução de medidas associadas às reformas educativas.

Ressalta-se a tendência do Banco Mundial de supostamente conhecer a realidade socioeconômica e educacional dos países em desenvolvimento. Essa condição lhe confere determinada autoridade para influenciar na proposição de reformas para a educação (CORAGGIO, 1998). No âmbito da economia, mesmo com histórico escasso na produção de conhecimento inovador, o Banco Mundial

[...] desfruta de legitimidade com bastião de expertise em matéria de desenvolvimento. Suas publicações são referência no mundo inteiro para gestores públicos, pesquisadores e formadores de opinião nas mais diversas áreas. [...] Embora cultive a aparência de excelência técnica, a pesquisa realizada pelo Banco Mundial é altamente normativa, servindo para a instituição fazer proselitismo de sua agenda política. De fato, a atividade intelectual do Banco Mundial não se submete às regras do campo científico, regido pela revisão por pares e pela necessidade de se ter pluralidade de enfoques e visão ampla e balanceada das evidências. (PEREIRA, 2018, p. 3).

Além disso, Pereira (2018) ressalta que as pesquisas do Banco Mundial são respaldadas por suas próprias pesquisas anteriores, ou são encomendadas por ele. Para exemplificar, o relatório O Estado num mundo em transformação (1997) 
[...] é dedicado ao papel e à efetividade do Estado: o que o Estado deve fazer, como deve fazê-lo e como fazê-lo melhor num mundo que se está transformando rapidamente. Essas questões estão no topo da agenda dos países em desenvolvimento e industriais. (BANCO MUNDIAL, 1997, p. III).

A reforma do Estado articulou-se ao conjunto das reformas econômicas, ao mesmo tempo em que deu suporte à realização dos ajustes estruturais e setoriais. Assim sendo, as soluções inovadoras indicadas pelo Banco Mundial (1997) reafirmaram as medidas já previstas no Plano diretor da reforma do Estado (1995) ${ }^{5}$. Por isso, as diretrizes expostas no referido Plano estavam em sintonia com as do Banco Mundial (1997), reforçando o que tinha sido anunciado, principalmente em relação a capacidade de governabilidade ${ }^{6}$ do Estado, a qual seria alcançada por meio da

[...] transição programada de um tipo de administração pública, burocrática, rígida e ineficiente, voltada para si própria e para o controle interno, para uma administração pública gerencial, flexível e eficiente, voltada para o atendimento da cidadania. (BRASIL, 1995, p. 12).

A reforma da educação, a qual compõe o processo de reforma do Estado, também é justificada no relatório do Banco Mundial (1997), prioritariamente em relação ao ensino elementar, pois do ponto de vista econômico daria maior retorno social e, politicamente, seria sustentado pela relevância em promover a equidade. Do mesmo modo, a educação elementar/básica é entendida como aquela que, junto à saúde básica, pode promover o enfrentamento à pobreza e a desigualdade, que poderiam gerar instabilidade e violência. 0 relatório indica

As políticas e programas públicos devem não só gerar crescimento, mas também assegurar que sejam compartilhados os benefícios do crescimento fomentado pelo mercado, particularmente por meio de investimentos em serviços básicos de educação e saúde. (BANCO MUNDIAL, 1997, p. 4).

Reitera-se, nessa direção, que o relatório 0 Estado num mundo em transformação (1997) teve grande influência na reforma da educação básica e da gestão escolar na década de 1990, pois seria necessário estabelecer novos paradigmas de conhecimento e de aprendizagem. 0 "novo paradigma", amparado na pós-modernidade e, em parte, na ideologia da globalização e nos pressupostos liberais, ainda tem como central a continuidade da reforma da educação com o objetivo de adequá-la ao cenário cultural e econômico mundial, o qual vem sendo delineado desde a década de 1990 (ZANARDINI, I., 2007).

O Banco Mundial se sobressai,

\footnotetext{
5- 0 Plano diretor da reforma do aparelho do Estado (1995) foi o primeiro documento do MARE - Ministério de Administração e Reforma do Estado, tendo como um dos articuladores da reforma e modernização do Estado, Luiz Carlos Bresser Pereira.

6 - A governabilidade constituiria um critério fundamental para obter êxito nas reformas. No processo de implementação das políticas de ajuste, o Estado deveria garantir a estabilidade e a segurança do sistema. A ênfase na governabilidade está associada à capacidade do governo conduzir e realizar as políticas de ajuste definidas pelos organismos internacionais (LEHER, 1998).
} 
[...] expedindo diretrizes e implementando estratégias econômicas, políticas e ideológicas para o permanente movimento de reprodução do Capital, ditando regras para as ações do Estado e às políticas educacionais. Resultam da incorporação do receituário do Banco Mundial no Brasil as alterações nas políticas de avaliação, componentes, portanto, da própria reforma estatal. (ZANARDINI, J., 2008, p. 91).

Cabe refletir, portanto, sobre a margem de autonomia dos países que negociam créditos para selecionar quais políticas serão financiadas, quais insumos serão adquiridos, bem como quais serão as possíveis alternativas para atender às demandas educacionais. Nesse sentido, Fonseca (1998a, 1998b) destaca que na década de 1990 as estratégias para melhorar a educação estiveram relacionadas à aquisição de material didático, em detrimento de recursos humanos. Assim, as instituições financeiras reduziram a melhoria da qualidade da educação a um conjunto de regulamentos econômicos a serem introduzidos no setor educacional que são, na realidade, políticas intervencionistas que fragilizam as instituições nacionais (SILVA, 2000).

A educação básica tem sido estratégica para o Banco Mundial, considerada como fator determinante para reduzir a pobreza e proporcionar a equidade. 0 documento Retomando o caminho para a inclusão, o crescimento e a sustentabilidade (2016), faz um diagnóstico sistemático do Brasil sinalizando que é um dos países mais desiguais do mundo, no que diz respeito às oportunidades econômicas e o acesso aos serviços básicos. Contudo, reconhece que na última década os avanços socioeconômicos no Brasil foram notáveis sendo que, a partir de 2003, o país passou a ser reconhecido pelos avanços na redução da pobreza, em que milhões de pessoas saíram da miséria:

Entre 2002 e 2010, cerca de dois terços do crescimento do PIB foram decorrentes de aumentos na quantidade e na qualidade dos insumos de mão de obra, que, em média, acresceram 2,7 pontos percentuais ao crescimento médio, conforme o Brasil passava por uma transição demográfica acelerada e colhia os frutos da ampliação do acesso à educação. (BANCO MUNDIAL, 2016, p. xviii).

A melhoria do acesso à saúde e à educação básicas e as crescentes transferências sociais contribuíram para reduzir a pobreza e diminuir a desigualdade no Brasil ao longo da década de 2000. Todavia, o Banco Mundial (2016) assinala que ainda persiste a baixa qualidade do ensino público. 0 Informe sobre el desarrollo mundial 2018 - Mensajes principales: aprender para hacer realidad la promesa de la educación (2017) aponta que

As crianças de lares marginalizados são as que mais necessitam de uma boa educação para prosperar na vida. Mas sem aprendizagem, a educação não pode ser o fator determinante para pôr fim à pobreza e promover a prosperidade compartilhada ${ }^{7}$. (BANCO MUNDIAL, 2017a, p. 1, tradução nossa).

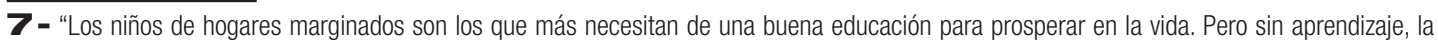
educación no puede ser el factor determinante para poner fin a la pobreza y fomentar la prosperidad compartida" (BANCO MUNDIAL, 2017a, p. 1) 
Na mesma direção, o Banco Mundial (2017a) sustenta que os resultados da aprendizagem são, quase sempre, muito piores entre a população de baixa renda, sendo que muitas das crianças provenientes dessas famílias nem sequer têm acesso à escola. Nessa lógica, esses graves problemas constituem uma "crise da aprendizagem". Diante disso, as três dimensões da "crise da aprendizagem" são assim definidas:

A primeira são os resultados da aprendizagem pouco satisfatórios. [...] A segunda dimensão da crise da aprendizagem são suas causas imediatas, que nas escolas se manifestam na quebra da relação entre o ensino e a aprendizagem. [...] A terceira dimensão da crise são suas causas sistêmicas mais profundas [...] muitas das causas mais profundas da crise da aprendizagem são de natureza política ${ }^{8}$. (BANCO MUNDIAL, 2017a, p. 1-3, tradução nossa).

No tocante à segunda dimensão da “crise da aprendizagem”, são identificados quatro aspectos que a produzem:

As crianças não chegam à escola preparadas para aprender. A desnutrição, as doenças, os escassos investimentos dos pais e as difíceis condições associadas à pobreza prejudicam a aprendizagem na primeira infância. [...] Muitas vezes os professores não têm as competências nem a motivação para ensinar de maneira eficaz. Os professores são o principal fator que afeta a aprendizagem nas escolas. [...] Frequentemente, os materiais não chegam às salas de aula ou, quando estão disponíveis, não têm efeito na aprendizagem. [...] Uma má administração e governança tendem a prejudicar a qualidade da escolarização (BANCO MUNDIAL, 2017a, p. 2, tradução nossa, grifo do autor).

Apresentadas as dimensões e os aspectos da "crise da aprendizagem", o Informe sobre el desarrollo mundial 2018: aprender para hacer realidad la promesa de la educación (2018) propõe que a mudança dos resultados insatisfatórios depende dos sistemas de ensino que devem pôr em prática três estratégias que

[...] constituem o $\mathrm{ABC}$ das reformas educacionais bem-sucedidas:

- Aprender mais sobre o nível de aprendizagem para que sua melhoria seja um objetivo formal

e mensurável. Medir melhor a aprendizagem e melhorar seu acompanhamento; utilizar esses resultados para orientar as medidas que devem ser adotadas.

- Basear a elaboração das políticas em evidências para fazer com que as escolas estejam à serviço da aprendizagem de todos os estudantes. Utilizar a evidência para orientar a inovação e a prática.

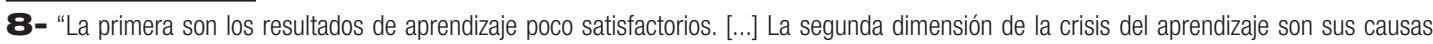
inmediatas, que en las escuelas se manifiestan en el quiebre de la relación entre la enseñanza y el aprendizaje. [...] La tercera dimensión de la crisis son sus causas sistémicas más profundas [...] muchas de las causas más profundas de la crisis del aprendizaje son de naturaleza política" (BANCO MUNDIAL, 2017a, p. 1-3).

9- "Los niños no llegan a la escuela preparados para aprender. La malnutrición, las enfermedades, las escasas inversiones parentales y las difíciles condiciones asociadas con la pobreza menoscaban el aprendizaje en la primera infancia. [...] A menudo los docentes no tienen las competencias ni la motivación para enseñar de manera eficaz. Los docentes son el principal factor que afecta el aprendizaje en las escuelas. [...] Con frecuencia, los insumos no llegan a las aulas o, cuando se cuenta con ellos, no tienen un efecto en el aprendizaje. [...] Una mala administración y gobernanza suelen menoscabar la calidad de la escolarización" (BANCO MUNDIAL, 2017a, p. 2).
} 
- Construir coalizões e alinhar aos atores para que todo o sistema favoreça a aprendizagem. Enfrentar os obstáculos técnicos e políticos que impedem a aprendizagem em escala ${ }^{10}$. (BANCO MUNDIAL, 2018, p. 16, tradução nossa, grifo do autor).

Diante disso, para o Banco Mundial a "escolarização sem aprendizagem é uma lamentável perda de recursos valiosos e de potencial humano. E o que é ainda pior, constitui uma injustiça. Sem aprendizagem, os estudantes estão condenados a viver na pobreza e na exclusão"11 (BANCO MUNDIAL, 2018, p. v, tradução nossa). Por conseguinte, assevera que as reformas na educação permitem aos países usufruírem dos benefícios gerados pela educação como o crescimento econômico a longo prazo, preparando as pessoas para a vida e para o trabalho.

0 conceito de aprendizagem presente nas propostas e reformas neoliberais é de caráter instrumental e dissolve a função do ensino, da apropriação da cultura e da ciência historicamente acumuladas. Conforme Libâneo (2012), o conceito de aprendizagem, para o Banco Mundial, expressa por um lado uma visão restrita ao se referir a aprendizagens mínimas, ou seja, competências básicas para a sobrevivência; e da mesma forma expressa uma visão ampliada, no sentido de ultrapassar o âmbito escolar e cognitivo, incluindo as vivências e a aprendizagem ao longo da vida, ou seja, de modo permanente.

Conforme a lógica do Banco Mundial (2017a), a recompensa pelos esforços em implantar e implementar as políticas educacionais baseadas nos princípios propostos, é de uma educação que ajude no crescimento e no desenvolvimento sustentado. A educação de qualidade impulsionaria o crescimento econômico e promoveria o emprego, a renda, a saúde e a redução da pobreza. As habilidades e as competências adquiridas durante a formação escolar é que proporcionariam os recursos individuais para o trabalho e para a vida e não apenas o tempo despendido na escola.

Todavia, subjacente à indicação da necessidade de promover reformas institucionais e administrativas na Educação, observa-se, ainda, o parâmetro da racionalidade econômica que, desde a década de 1970, “[...] destaca a necessidade de apoiar o desenvolvimento de métodos de aprendizagem que permitam economizar recursos, bem como de estimular os países, cujas taxas de escolarização primária são baixas, a realizar uma revisão das estruturas educacionais" (FIGUEIRED0, 2009, p. 1132).

Por outro lado, o relatório Um ajuste justo: Análise da eficiência e equidade do gasto público no Brasil (2017) apresenta um diagnóstico dos gastos públicos e aponta que o governo brasileiro gasta mal e mais do que pode. Este relatório responde a uma demanda do governo federal, em 2016, que solicitou ao Banco Mundial a elaboração do documento

10 - "[...] constituyen el $\mathrm{ABC}$ de las reformas educativas exitosas:

- Aprender más sobre el nivel de aprendizaje para que su mejora sea un objetivo formal y medible. Medir mejor el aprendizaje y mejorar su seguimiento; utilizar esos resultados para orientar las medidas que deban adoptarse.

- Basar el diseño de políticas en la evidencia para lograr que las escuelas estén al servicio del aprendizaje de todos los estudiantes. Utilizar la evidencia para orientar la innovación y la práctica.

- Construir coaliciones y alinear a los actores para que todo el sistema favorezca el aprendizaje. Abordar los obstáculos técnicos y políticos que impiden el aprendizaje a escala" (BANCO MUNDIAL, 2018, p. 16, grifo do autor).

11- "Escolarización sin aprendizaje es una lamentable pérdida de recursos valiosos y de potencial humano. Y lo que es aún peor, constituye una injusticia. Sin aprendizaje, los estudiantes estarán condenados a vivir en la pobreza y la exclusión" (BANCO MUNDIAL, 2018, p. v). 
que visasse uma análise da eficiência e da equidade do gasto público no Brasil, o qual apontou alternativas para reduzir o déficit fiscal. Um argumento observado é o de que alguns programas sociais estariam beneficiando aos ricos, não atingindo de forma eficaz aos objetivos preconizados pelo próprio Banco Mundial. Por isso, propõe economizar parte do orçamento e implementar um "ajuste justo" para conquistar uma "trajetória sustentável" com as contas fiscais brasileiras.

No tocante à educação, o relatório argumenta:

As despesas públicas com ensino fundamental e médio apresentam ineficiências significativas, e o mesmo nível de serviços poderia ser prestado gastando $1 \%$ a menos do PIB em nível local. Uma análise de eficiência intermunicipal demonstra que o desempenho atual dos serviços de educação poderia ser mantido com 37\% menos recursos no Ensino Fundamental e 47\% menos recursos no Ensino Médio. Isso corresponde a uma economia de aproximadamente 1\% do PIB. As baixas razões aluno/professor representam a principal causa de ineficiência (39\% da ineficiência total). 0 aumento do número de alunos por professor em 33\% no Ensino Fundamental e 41\% no Ensino Médio economizaria R\$ 22 bilhões (0,3\% do PIB) por ano. (BANCO MUNDIAL, 2017b, p. 13, grifos do autor).

Nesse sentido, aponta que no Brasil se gasta mais do que o necessário com os ensinos fundamental e médio, e que a redução do gasto poderia ser feita por meio do aumento do número de alunos por professor, pois a baixa razão professor/aluno seria a principal causa de ineficiência. Essa ineficiência seria resolvida, portanto, pela não contratação de profissionais para substituir aqueles que deixarão o cargo futuramente. Outra indicação diz respeito ao aumento do tempo em atividades de ensino para o professor e, no caso, o tempo em sala de aula seria uma resposta ao ajuste necessário.

0 que tem ocorrido, no caso, é um alargamento no conceito de docência, em que docência e a gestão fazem parte da formação do licenciado em pedagogia. No projeto de formação de professores, por parte dos Organismos Internacionais/Multilaterais, prevalece a ênfase no controle de resultado, na aquisição de competências e no excesso de responsabilidades. Essa amplitude de funções confugira o "superprofessor"12. Portanto, ao que tudo indica, para "[...] a pedagogia do capital em andamento supõe convencer os professores de que sua intervenção, de fato, solucionará os problemas socioeconômicos do país" (EVANGELISTA; LEHER, 2012, p. 13). Assim, se propala que a educação pública é de má qualidade, em parte, porque os professores não têm a competência e/ou a motivação necessária para ensinar.

Deve ser destacado que as mudanças recentes no curso de pedagogia, relacionadas a ampliação das funções do licenciado em pedagogia, incorporam diretrizes de Organismos Internacionais e fazem parte do conjunto de reformas do Estado que visam adaptar a educação às demandas neoliberais. São defınidas nas Diretrizes Curriculares Nacionais

12 - Em relação ao "superprofessor", cumpre esclarecer que "Seu sentido é oferecido por um duplo papel: objeto da reforma, dado que ela atua modificando o papel do professor, e instrumento da reforma, posto que será por meio dele que a reforma será implementada. Ou seja, um movimento contraditório que mostra a relação existente entre o superprofessor e o professor-instrumento que, sendo objeto da reforma, é responsável por sua execução" (EVANGELISTA; TRICHES, 2012, p. 194). 
para o Curso de Graduação em Pedagogia (DCNP), efetivadas por meio da Resolução CNE/ CP nº 01/2006 (EVANGELISTA; TRICHES, 2012, p. 186).

Outro aspecto mencionado no relatório Um ajuste justo: Análise da eficiência e equidade do gasto público no Brasil (2017) é de que

A vinculação constitucional dos gastos em educação a 25 por cento das receitas dos municípios pode ser uma das principais causas da ineficiência dos gastos. [...] é provável que para cumprir as regras constitucionais, muitos municípios ricos sejam obrigados a gastar em itens que não necessariamente ampliem o aprendizado. [...] Com a rápida queda da taxa de fertilidade para menos de 1.8, o número de alunos vem caindo rapidamente em muitos municípios, principalmente no Ensino Fundamental. Dado que essa queda do número de alunos não está necessariamente associada a uma queda das receitas correntes líquidas, isso implica que para cumprir a lei, muitos municípios são obrigados a gastar mais e mais por aluno, mesmo que esse gasto adicional não seja necessário. (BANCO MUNDIAL, 2017b, p. 13, grifos dos autores).

Conforme o exposto, a queda na taxa de natalidade provocou a redução de matrículas no ensino fundamental, sendo que a queda nas matrículas não foi acompanhada pela queda das receitas correntes líquidas. 0 que o Banco Mundial (2017b) infere é que o Estado, ao continuar garantindo um percentual mínimo das receitas, apesar da queda das matrículas, estaria, mais uma vez, sendo ineficiente.

Assim, em dezembro de 2016 o Congresso Nacional aprovou a Emenda Constitucional No 95 que limita os gastos federais com despesas primárias e prevê proporcionar maiores gastos com despesas não primárias. As despesas primárias dizem respeito aos gastos com a manutenção do Estado e com os serviços públicos, enquanto as despesas não primárias são as despesas financeiras, como a dívida pública. 0 relatório Um ajuste justo: análise da eficiência e equidade do gasto público no Brasil (2017) aponta que

[...] ela [a Emenda Constitucional № 95/2016] não garante a concepção, qualidade e aplicação das reformas fiscais necessárias para cumprir a trajetória de ajustes estabelecida pela regra. Uma vez que o limite para o crescimento dos gastos é aplicado somente às despesas primárias agregadas (e não a seus componentes ou programas específicos), ele não oferece orientação sobre onde reduzir os gastos. Nesse contexto, é fundamental determinar quais despesas devem ser reduzidas devido a sua eficácia limitada, sua incidência regressiva e seu impacto negativo sobre a produtividade, em vez de concentrar as reduções nos itens que podem ser cortados mais facilmente. A qualidade do ajuste fiscal terá repercussões na prestação de serviços públicos, na equidade e no crescimento econômico. (BANCO MUNDIAL, 2017b, p. 33, grifo dos autores).

Desse modo, ao mesmo tempo em que se proclama a educação como elemento central para a redução da pobreza e para o desenvolvimento sustentado, o Banco Mundial afirma no relatório Um ajuste justo, que os gastos com a educação no Brasil podem e devem ser reduzidos. Conforme aponta, a destinação de um percentual da receita resulta em gastos desnecessários, uma vez que o número de matrículas no ensino fundamental tem sido reduzido em decorrência da queda da taxa de natalidade. Pontua, ainda, que 
"As despesas com ensino superior são, ao mesmo tempo, ineficientes e regressivas. Uma reforma do sistema poderia economizar 0,5\% do PIB do orçamento federal" (BANCO MUNDIAL, 2017b, p. 13, grifo dos autores), tendo como proposta a cobrança de taxas/ mensalidades no ensino das universidades públicas.

0 relatório do Banco Mundial (2017b) sinaliza que os resultados da Educação no Brasil têm melhorado, entretanto são baixos se se considerar o aumento dos gastos. Na mesma direção identifica-se, ainda, as seguintes ponderações:

A ineficiência do gasto em educação básica no Brasil é elevada e vêm aumentando. [...] O baixo desempenho do sistema educacional brasileiro reflete-se nas altas taxas de reprovação e evasão escolar, apesar das baixas e decrescentes razões aluno-professor. [...] 0 baixo indice de conclusão do ensino médio é outro indicador do baixo desempenho do sistema educacional. [...] A alta defasagem escolar tem inicio no ensino fundamental e prossegue até o ensino superior, o que resulta em um alto custo médio para formar um aluno. [...] A baixa qualidade dos professores é o principal fator restringindo a qualidade da educação. [...] A ineficiência dos ensinos fundamental e médio está principalmente relacionada ao número excessivo de professores. [...] Professores no Brasil dedicam uma parte do tempo em atividades pouco produtivas. Em média, professores usam somente 65\% de seu tempo para ensinar, ao passo que, segundo melhores práticas internacionais, o ideal seria 85\%. (BANCO MUNDIAL, 2017b, p. 124-130, grifo dos autores).

Reitera-se a proposição do Banco Mundial em não reduzir o número de alunos em sala, bem como em não aumentar o salário dos professores. Recomenda o aumento do tempo de dedicação dos professores em sala de aula como uma das formas de reduzir as taxas de reprovação e evasão escolar. Esse aspecto entra em contradição com a afirmação do Banco Mundial (2017a) de que os professores são os principais responsáveis pela aprendizagem e que muitos não tem as competências e a motivação para ensinar com eficácia.

A educação é considerada pelo Banco Mundial como um fator determinante para o combate à pobreza. Entretanto, no relatório Um ajuste justo: análise da eficiência e equidade do gasto público no Brasil (2017) duas constatações são pertinentes, a saber: os gastos públicos com educação podem e devem ser reduzidos e a qualidade ${ }^{13}$ da educação brasileira é considerada baixa. Isso proporciona "[...] a intervenção de grupos privados nos sistemas públicos de ensino, supostamente portadores da varinha de condão cujo toque conduzirá a educação à 'boa qualidade', afınal, os empresários sabem buscar resultados." (EVANGELISTA; LEHER, 2012, p. 12).

0 viés economicista no enfoque do Banco Mundial na educação não está relacionado, necessariamente, aos aspectos econômicos do sistema educativo. Se expressa, no entanto, em questões inerentes às políticas formuladas e respondidas por meio da mesma teoria e metodologia com as quais se buscam responder à economia de mercado. A tentativa de enquadrar o sistema educacional ao sistema de mercado, de estabelecer as relações entre escola e empresa, entre pais, alunos e consumidores de

13- A discussão sobre qualidade na Educação é ampla e o conceito é uma construção histórica que assume significados distintos em tempos e espaços diferentes. Conferir, dentre outros: Dourado, Oliveira e Santos (2007). 
serviços, entre as relações pedagógicas e produtos, é que imprime um viés economicista na educação (CORAGGIO, 1998).

Além da produção intelectual, o Banco Mundial oferece uma cooperação que inclui o desenvolvimento de projetos de financiamento. Nesse caso, é possível observar, portanto, que permanece atualizada a indagação de Fonseca (1998b) sobre a pertinência da cooperação internacional como alternativa ao Estado para propor projetos temporários e limitados financeira e geograficamente, concebidos como solução para os problemas estruturais, que nem mesmo o Estado resolveu.

\section{Considerações finais}

Nos limites deste artigo, buscou-se discutir as proposições do Banco Mundial para a política educacional brasileira entre os anos 2016 e 2018. Ao que tudo indica, a preocupação com a educação básica tem sido de caráter estratégico para o alívio da pobreza, a manutenção da força de trabalho e o aumento da produtividade dos pobres, por meio da aquisição de habilidades e competências mínimas. Do mesmo modo, ao buscar amenizar os efeitos da pobreza, a oferta dos serviços básicos, particularmente de educação e de saúde, dissimula os problemas de ordem estrutural que causam a desigualdade social.

As atuais proposições do Banco Mundial, estudadas neste artigo, têm incorporado o discurso de alívio da pobreza em que o atendimento das necessidades educacionais básicas é considerado como uma das variáveis fundamentais para a administração dos níveis de pobreza e a promoção da equidade. Por outro lado, propõe a reforma no Estado e, portanto, da educação, concebida como uma das responsáveis pela suposta ineficiência dos gastos públicos no Brasil.

0 Banco Mundial exerce função expressiva na produção de conhecimento para e sobre os países, além de atuar na concessão de empréstimos. A produção intelectual influencia na formulação de políticas nos países membros. Pode-se inferir a existência de um confronto entre os argumentos de aliviar a pobreza e os objetivos de minimizar os gastos públicos.

As proposições do Banco Mundial demonstram o alinhamento de um projeto societário neoliberal em que os fundamentos das análises realizadas estão relacionados a gestão das políticas de ajuste econômico. As políticas implementadas na década de 1990 encontram respaldo, na atualidade, para concretização dos objetivos para além da correlação de forças nacionais.

A “crise”, quando deslocada para a aprendizagem, enaltece a individualidade que é sustentada, pelos argumentos do Banco Mundial, a partir da Teoria do Capital Humano. 0 conceito de aprendizagem, nas proposições e reformas neoliberais, expressa um caráter instrumental e dissolve a função do ensino, da apropriação da cultura e da ciência historicamente acumuladas.

Há também um deslocamento do conceito de escolaridade para o de aprendizagem. Assim, ao que tudo indica, o Banco Mundial reforça que os resultados da aprendizagem independem de questões estruturais e físicas das escolas. Do mesmo modo, reforça a defesa de potencializar o trabalho docente por meio do aumento do número de alunos 
em sala, visando a redução dos custos da educação. A ideia de "aprendizagem ao longo da vida" respalda o conceito de empregabilidade. Nesse caso, o Banco Mundial argumenta que o aumento da produtividade dos pobres se dá por meio da aquisição de habilidades e competências.

A partir da década de 1990, na produção intelectual do Banco Mundial, a educação básica tende a continuar como elemento central para o alívio da pobreza e promoção da equidade. Contudo, o Banco Mundial afırma a ineficiência da educação como expressão da ineficiência do Estado e da má utilização de recursos públicos. Com isso, retoma-se os preceitos do Estado avaliador e da gestão por resultados, evidenciando que a continuidade do processo de reformas torna-se mais contundente.

\section{Referências}

ARRUDA, Marcos. ONGs e o Banco Mundial: é possível colaborar criticamente? In: TOMMASI, Lívia.; WARDE, Mirian Jorge; HADDAD, Sergio (org.). 0 Banco Mundial e as políticas educacionais. 2. ed. São Paulo: Cortez, 1998. p. 41-73.

BANCO MUNDIAL. Informe sobre el desarrollo mundial 2018 - Mensajes principales: Aprender para hacer realidad la promesa de la educación. Washington, DC. 2017a. 4 p.

BANCO MUNDIAL. Informe sobre el desarrollo mundial 2018: aprender para hacer realidad la promesa de la educación. Washington, DC: Banco Mundial, 2018. Disponível em: https://openknowledge.worldbank. org/handle/10986/28340 Acesso em: 20 jul. 2018.

BANCO MUNDIAL. 0 Estado num mundo em transformação: relatório sobre o desenvolvimento mundial 1997. Washington, DC: Banco Mundial, 1997.

BANCO MUNDIAL. Retomando o caminho para a inclusão, o crescimento e a sustentabilidade: relatório No 101431-BR: Brasil - Diagnóstico sistemático de país. Washington, DC: Banco Mundial, 2016.

BANCO MUNDIAL. Um ajuste justo: análise da eficiência e equidade do gasto público no Brasil. Síntese. v. 1. Washington, DC: Banco Mundial, 2017b.

BRASIL. Conselho Nacional de Educação. Resolução CNE/CP n. 1, de 15 de maio de 2006. Institui Diretrizes Curriculares Nacionais para o Curso de Graduação em Pedagogia, licenciatura. 2006. Diário Oficial da União, Brasília, DF, , Seção 1, p. 1-11, 16 maio 2006.

BRASIL. Ministério da Administração Federal e Reforma do Estado. Plano diretor da reforma do aparelho do Estado. Brasília, DF: MARE, 1995.

CORAGGI0, José Luis. Propostas do Banco Mundial para a educação: sentido oculto ou problemas de concepção? In: WARDE, Mirian Jorge; HADDAD, Sergio (org.). 0 Banco Mundial e as políticas educacionais. Tradução de Mônica Corullón. 2. ed. São Paulo: Cortez, 1998. p. 75-123. 
DEITOS, Roberto Antonio. Políticas públicas e educação: aspectos teórico-ideológicos e socioeconômicos. Acta Scientiarum Education, Maringá, v. 32, n. 2, p. 209-218, 2010.

DOURADO, Luiz Fernando; OLIVEIRA, João Ferreira de; SANTOS, Catarina de Almeida. A qualidade da educação: conceito e definições. Brasília, DF: INEP, 2007.

EVANGELISTA, Olinda; LEHER, Roberto. Todos Pela Educação e o episódio Costin no MEC: a pedagogia do capital em ação na política educacional brasileira. Trabalho Necessário, Niterói, v. 10, n. 15, p. 1-29, 2012.

EVANGELISTA, Olinda; TRICHES, Jocemara. Curso de pedagogia, organizações multilaterais e 0 superprofessor. Educar em Revista, Curitiba, n. 45, p. 185-198, jul./set. 2012.

FIGUEIRED0, Ireni Marilene Zago. Desenvolvimento, globalização e políticas sociais: um exame das determinações contextuais dos projetos de reforma da educação e saúde brasileiras da última década. 2006. 264 f. Tese (Doutorado em Educação - História, Filosofia e Educação) - Universidade Estadual de Campinas, Campinas, 2006.

FIGUEIREDO, Ireni Marilene Zago. Os projetos financiados pelo Banco Mundial para o Ensino Fundamental no Brasil. Educação \& Sociedade, Campinas, v. 30, n. 109, p. 1123-1138, set./dez. 2009.

FONSECA, Marília. 0 Banco Mundial como referência para a justiça social no terceiro mundo: evidências do caso brasileiro. Revista da Faculdade de Educação, São Paulo, v. 24, n. 1, jan./jun. 1998a. p. 37-69.

FONSECA, Marília. 0 Banco Mundial e a educação brasileira: uma experiência de cooperação internacional. In: OLIVEIRA, Romualdo Portela de (org.). Política educacional: impasses e alternativas. 2. ed. São Paulo: Cortez, 1998b. p. 85-121.

FRIGOTTO, Gaudêncio; CIAVATTA, Maria. Educação básica no Brasil na década de 1990: subordinação ativa e consentida à lógica do mercado. Educação \& Sociedade, Campinas, v. 24, n. 82, p. 93-130, abr. 2003.

GRUPO BANCO MUNDIAL. Quiénes somos. [S. I.: s. n.], 2019. Disponível em: http://www.bancomundial. org/es/who-we-are. Acesso em: 10 out. 2019.

GUERRA, Dhyovana. Contenção e liberação na política educacional brasileira: tendências predominantes na política de educação infantil e do ensino fundamental (2006-2016). 2020. 152 f. Dissertação (Mestrado em Educação) - Universidade Estadual do Oeste do Paraná, Cascavel, 2020.

LEHER, Roberto. Da ideologia do desenvolvimento à ideologia da globalização: a educação como estratégia do Banco Mundial para "alívio" da pobreza. São Paulo. 1998. Tese (Doutorado em Educação Administração) - Universidade de São Paulo, São Paulo, 1998.

LIBÂNEO, José Carlos. 0 dualismo perverso da escola pública brasileira: escola do conhecimento para os ricos, escola do acolhimento social para os pobres. Educação e Pesquisa, São Paulo, v. 38, n. 1, p. 13-28, 2012. 
OLIVEIRA, Dalila Andrade; FONSECA, Marília. 0 Banco Mundial e as políticas de formação docente: a centralidade da educação básica. In: HIDALGO, Angela Maria; SILVA, lleizi Luciana Fiorelli (org.). Educação e Estado: as mudanças nos sistemas de ensino do Brasil e Paraná na década de 90. Londrina: UEL, 2001. p. 41-68.

PEREIRA, João Márcio Mendes. Dimensões da história do Banco Mundial como ator político, intelectual e financeiro. Cadernos de Saúde Pública, Rio de Janeiro, v. 34. n. 2. p. 1-4, 2018.

PEREIRA, João Márcio Mendes. 0 Banco Mundial como ator político, intelectual e financeiro (19442008). 2009. 382 f. Tese (Doutorado) - Universidade Federal Fluminense, Rio de Janeiro, 2009.

SHIROMA, Eneida Oto; MORAES, Maria Célia Marcondes; EVANGELISTA, Olinda. Política educacional. 3. ed. Rio de Janeiro: Lamparina. 2011.

SILVA, Maria Abádia da. A hegemonia do Banco Mundial na formulação e no gerenciamento das políticas educacionais. Nuances, Presidente Prudente, v. 6. p. 35-53, out. 2000.

SILVA, Maria Abádia da. Intervenção e consentimento: a política educacional do Banco Mundial. Campinas: Autores Associados; São Paulo: Fapesp. 2002.

TOMMASI, Lívia. Financiamentos do Banco Mundial no setor educacional brasileiro: os projetos em fase de implementação. In: TOMMASI, Lívia; WARDE, Mirian Jorge; HADDAD, Sergio (org.). 0 Banco Mundial e as políticas educacionais. 2. ed. São Paulo: Cortez, 1998. p. 195-227.

ZANARDINI, Isaura Mônica Souza. A reforma do Estado e da educação no contexto da ideologia da pósmodernidade. Revista Perspectiva, Florianópolis, v. 25, n. 1, p. 245-270, jan./jun. 2007.

ZANARDINI, João Batista. Ontologia e avaliação da educação básica no Brasil (1990-2007). 2008. 208 f. Tese (Doutorado em Educação) - Universidade Federal de Santa Catarina, Florianópolis, 2008.

Recebido em: 25.11.2019

Revisado em: 01.09.2020

Aprovado em: 20.10.2020

Dhyovana Guerra é doutoranda em educação pela Universidade Estadual do Oeste do Paraná (Unioeste). Fez graduação em pedagogia e mestrado em educação na Unioeste, Campus de Cascavel. É pesquisadora no Grupo de Estudos e Pesquisas em Política Educacional e Social (GEPPES).

Ireni Marilene Zago Figueiredo é doutora em educação pela Universidade Estadual de Campinas (Unicamp). É docente do Programa de Pós-Graduação em Educação e do Colegiado de Pedagogia da Universidade Estadual do Oeste do Paraná (Unioeste) e pesquisadora no GEPPES. 